\title{
Relationships Among Non-Cognitive Factors and Academic Performance: Testing the Consortium on Chicago School Research Model
}

Dana Wanzer, Elyse Postlewaite, \& Nazanin Zargarpour

March 4, 2019

Author Note: Please contact Dana Wanzer if you have any comments, feedback, or suggestions for this manuscript at dana@danawanzer.com. 


\begin{abstract}
In response to interest in the role of non-cognitive factors in academic performance, several theoretical models have been developed; however, there have been few empirical attempts to validate those models particularly with majority minority populations. This study used measures of academic mindsets, social skills, academic perseverance, learning strategies, and academic performance, with high school students from a mainly Hispanic, low-income school district, to test the structural pathways of a well-known hypothesized model of non-cognitive factors and academic performance proposed by researchers at the University of Chicago Consortium on Chicago School Research (Farrington et al., 2012). Results support the hypothesized model; however, academic perseverance was not significantly related to academic performance in the context of other non-cognitive factors. Additionally, we found that the model differed based on several group differences including age (e.g., freshman vs senior), socioeconomic status (e.g., parent education, free/reduced priced lunch), and race/ethnicity. Overall, this study confirms that non-cognitive factors have a role to play in students' academic success and finds that group difference factors are associated with the nature and strength of those relationships.
\end{abstract}




\section{Relationships Among Non-Cognitive Factors and Academic Performance: Testing the Consortium on Chicago School Research Model}

Non-cognitive factors have gained mounting recognition and importance in education due to their potential for positive impact on students' academic performance and success in adulthood (e.g., Garcia, 2014; Gutman \& Schoon, 2013; Weissberg, Durlak, Domitrovich, \& Gullotta, 2015). Schools are being asked to measure students on a single non-cognitive factor as an accountability metric as part of the Every Student Succeeds Act (ESSA) legislation. However, the implementation of non-cognitive factors in education is moving forward before findings have solidified fully and consensus among researchers has been reached as to specific associations between these competencies and outcomes of interest in various contexts and for diverse groups. Additionally, previous studies have examined many non-cognitive factors individually, whereas, it is more likely that these competencies interact with one another (Farrington et al., 2012). For the practitioner of education, working with a wide range of non-cognitive skills, a more coherent model would be helpful for effective application. Various models of non-cognitive factors and their relationships with academic performance have been offered throughout the years (e.g., CASEL, n.d.; Jones \& Bouffard, 2012) without sufficient empirical studies testing these models. This study aims to test empirically one such model.

Studies of potential influencing factors (e.g., SES and race/ethnicity) on the development of non-cognitive factors in relation to academic performance largely have been lacking (Durlak, Weissberg, Dymnicki, Taylor, \& Schellinger, 2011; Hoffman, 2009; Jones \& Bouffard, 2012). Early generalizations of findings are occurring despite relatively few studies that look at noncognitive factors across diverse settings and populations. Moreover, findings from the few studies are mixed (Credé, Tynan, \& Harms, 2016; Garner, Mahatmya, Brown, \& Vessely, 2014). 
There is a need to examine these models more closely, especially the individual and group difference factors (Sisk, Burgoyne, Sun, Butler, \& Macnamara, 2018) that may moderate the effects of non-cognitive factors on academic performance. This study focuses on those effects among a predominantly low-income, first-generation population.

Development of non-cognitive skills is complex, and studies examining their development must account for this complexity. Traditionally, this body of research tends to examine these phenomena with the traditional psychological research approach: studying single pathways to and from non-cognitive factors. However, a new approach is needed to understand the complex interworking of the individual in their context, over time. A more recent approach to psychological studies, Developmental Systems Theory (DST), considers “[how] mutually influential relations between individuals and contexts regulate the course of developmental change" (Lerner, Leonard, Fay, \& Issac, 2011, p. 146). DST is a relational metatheory, which provides an important lens through which to understand the complex nature of human development. It can provide a theoretical framework by which to study the role of non-cognitive factors in promoting academic performance while considering the contexts of individual or group differences that may impact their development.

The key components of the DST that frame this study are relationism, where each variable and system interacts in bidirectional, reciprocal, and/or fused ways; plasticity, the potential for an individual to change across the lifespan; and individual differences as the natural variability occurring from the fused interaction of genes and environment such that no two people are alike (Lerner, 1991). This theory provides a framework for researchers to ask: What individual characteristics in combination with contextual characteristics, from what levels of systems, at what points in time, will foster what instances of development, within what portions 
of the lifespan (Lerner et al., 2011, p. 157). This study uses DST as a framework to examine the interactions and relationships among non-cognitive factors with academic performance within the school context, while considering individual difference factors shared across groups (e.g., race/ethnicity and socioeconomic status), at different times across the early lifespan (e.g., for freshman and senior high school students).

The model of non-cognitive factors and academic performance for adolescents (youth aged 11-18) hypothesized by Farrington and colleagues (2012) at the University of Chicago Consortium on Chicago School Research (CCSR) provides a framework with which to study relational interactions in multiple contexts. The non-cognitive factors in the Farrington Model include academic mindsets, social skills, academic perseverance, and learning strategies which manifest through academic behaviors to predict academic performance (see Figure 1). School and classroom context factors, as well as student individual characteristics, are assumed to relate to the non-cognitive factors and are included in the model. However, the emphasis of the CCSR framework is placed on the relationships among the non-cognitive factors.

Importantly, this model lacks empirical testing and behooves inquiry as to whether or not it generalizes to diverse populations, which is the purpose of our study. This model was selected over other models for several reasons. First, it is parsimonious. Second, it is widely cited (over 500 citations). Third, from a DST perspective, it allows us to examine the relational component of interacting constructs; furthermore, the model is situated within contextual and individual factors. It is important to test this model to a) identify if the relationships exist empirically, b) understand for whom the relationships exist, and c) to isolate if any factors are more important than others for students' success. 


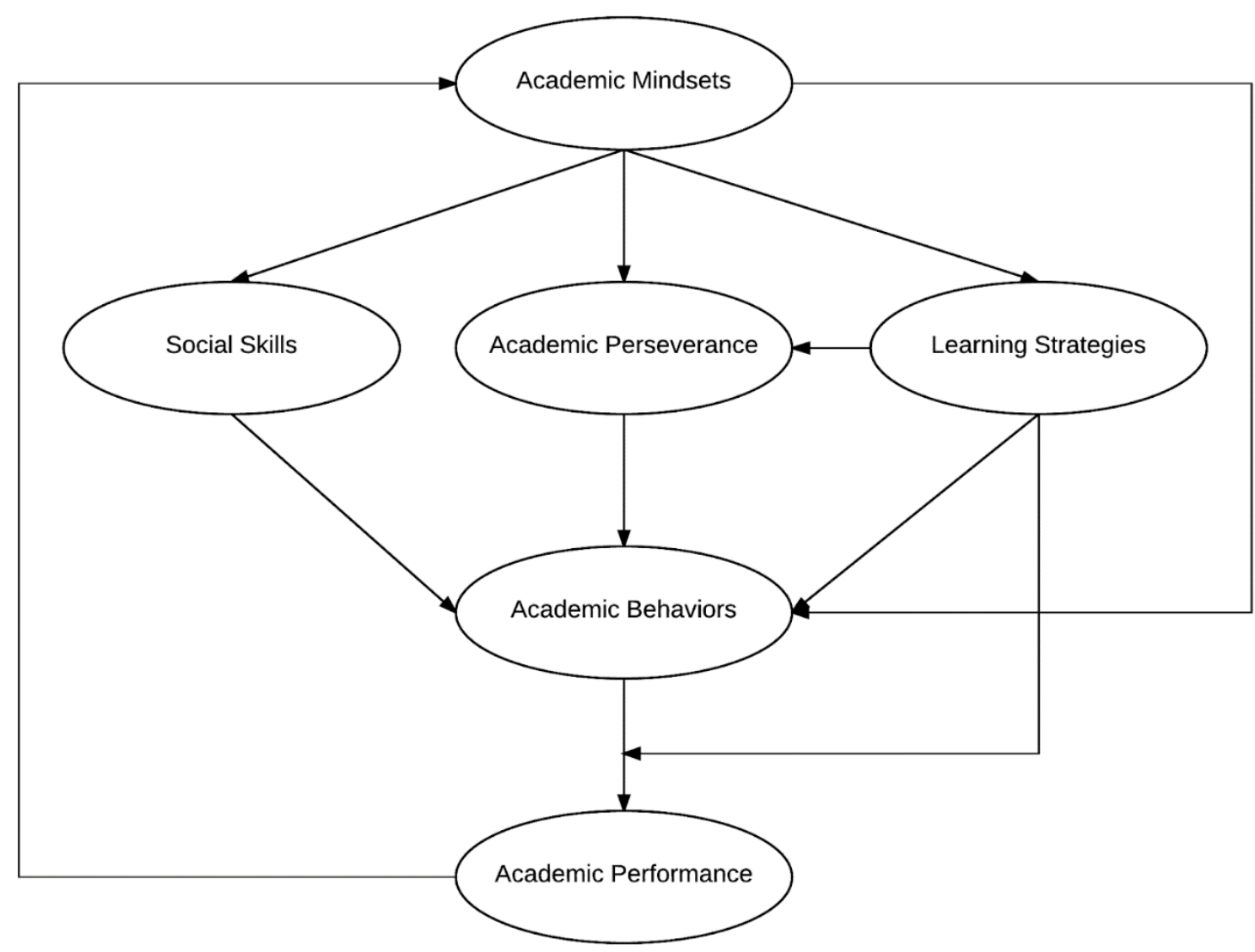

Figure 1. CCSR Hypothesized Model of how Non-Cognitive Factors Promote Academic Performance

A brief description of the CCSR hypothesized model is described below, followed by the rationale for the current study.

\section{Academic Behaviors}

Academic behaviors are most proximal to academic performance. Academic behaviors are described as student actions related to attending class, doing homework, and engaging in instructional activities. These behaviors are directly observable, making them relatively easy to monitor and thus, have been the focus of many interventions. They are also targeted in interventions because they are extremely important for academic performance and success. To learn content, skills, and knowledge, one would have to be physically present in the classroom 
and complete homework assignments. Additionally, the importance of academic behaviors is found in the fact that other non-cognitive factors almost always affect academic performance by working through academic behaviors. For example, academic mindsets do not directly impact academic performance, instead mindsets and attitudes toward learning can affect students' academic behaviors, such as how often a student shows up to class and how much effort they put into their schoolwork. These behaviors in turn can have an impact on academic performance. Therefore, academic behaviors can be construed as a mediator of cognitive and non-cognitive factors on academic performance.

\section{Academic Mindsets}

Academic mindsets are a conviction or belief about one's own abilities or sense of belongingness in the academic setting, which affect motivation, behavior, and performance both in positive and negative ways. For example, a student who does not identify with her fellow math students or the topic itself might struggle to see value in learning the subject and not be motivated to complete the homework (academic behavior), which in turn affects his or her grade (academic performance). As evident through this example, academic mindsets affect academic performance through academic behaviors.

CCSR identifies four important academic mindsets that play a role in academic behaviors and performance: 1) belongingness to the academic community, 2) growth mindset, 3) selfefficacy, and 4) value for academic work. As mentioned earlier, the relationship of academic mindsets to academic behaviors and performance is reciprocal. Doing well in a subject can validate and reinforce academic behaviors and mindsets for students (Yeager \& Walton, 2011). Academic mindsets are also related to the other non-cognitive factors. For example, a growth mindset is likely to boost one's continuing effort or determination to overcome obstacles in 
academics. Academic mindsets also drive learning strategy use, since an intrinsic value is needed to motivate and initiate learning strategies. Importantly, these mental attitudes can be triggered by contexts as seen with stereotype threat or learned helplessness (Aronson, Fried, \& Good, 2002). Significant gains in reducing the achievement gap have been found in mindset studies (Walton \& Cohen, 2011).

\section{Academic Perseverance}

Academic perseverance is the tenacity to achieve longer-term goals, resist distractions, as well as withstand challenges and overcome obstacles related to learning course material. Persistence, consistency, self-discipline, self-control, and delay of gratification have been found to be important for truly mastering a topic. A student must not only be able to show up for class but must also continue to attend class for their entire academic career despite any difficulties or obstacles.

Students' academic perseverance has been found to be context dependent in the classroom and likely interacts with the other non-cognitive factors (Farrington et al., 2012). Empirical work has begun to examine some of these relationships cross-sectionally. For example, learning strategies can impact academic perseverance. Strengthening or increasing students' repertoire of learning strategies can increase their likelihood to persist through obstacles or complications that arise (Bembenutty \& Karabenick, 1998). In another example, students' academic mindsets can impact their academic perseverance or tenacity (Farrington et al., 2012). A student with a positive outlook on their studies and their abilities is more likely to persevere in difficult settings (Dweck, Walton, \& Cohen, 2011).

\section{Learning Strategies}


Learning strategies, including students' abilities to self-regulate, set goals, employ study skills, and use metacognitive strategies, have convincing bodies of literature supporting their relationship to academic performance (e.g., metacognition see Hacker, Dunlosky, \& Graesser, 2009; self-regulated learning see Zimmerman \& Schunk, 1989). Learning strategies not only interact with other non-cognitive factors but also have reciprocal relationships with them (Farrington et al., 2012). For example, metacognition can increase competence, which can strengthen one's sense of self-efficacy, which, in turn, contributes to academic perseverance. On the other hand, students who have a greater sense of self-efficacy and value their academics are more likely to employ self-regulatory strategies and study skills. A major limitation of these studies is that they are mainly cross-sectional, making it difficult to determine a causal link. It may be that students who have high academic performance are able to employ learning strategies more effortlessly because they find the task or topic easy.

\section{Social Skills}

Finally, social skills have also been linked to positive academic performance, as social skills are described as positive interpersonal interactions, self-awareness and self-management, decision making, and improved behavior. As with the other non-cognitive factors, social factors have an indirect relationship to academic performance through students' behaviors. For example, students with a more highly developed sense of self, responsibility, and interpersonal skills may be more likely to have a positive, distraction-free experience in the classroom, resulting in greater attention given to learning and achievements (Farrington et al., 2012). Particularly in more collaborative classroom styles, social skills can enhance learning.

It is difficult to isolate the impact of social skills due to the overlap with the other noncognitive skills in the model (e.g., self-control). Moreover, the studies showing a link between 
social skills and academic performance tend to be correlational, meaning that we cannot be sure of a causal relationship. Additionally, it is possible that we see higher performance for students with developed social skills due to teachers rewarding good behavior. The good news is social skills have been found to be quite malleable through interventions.

\section{The Whole Model}

To generate accounts for behavior within development and to be able to make suggestions, we need to understand the bidirectional contributions of variables from multiple levels, which requires an integrative and multidisciplinary approach (Damon \& Lerner, 2009). Little research has examined noncognitive factors together along with their interrelated effect on academic performance. Therefore, the CCSR developed the present model by examining the research on each of the non-cognitive factors separately and the relationships between each noncognitive factor and academic performance.

One other study attempted to test a version of the CCSR model as a whole. Farruggia, Han, Watson, Moss, \& Bottoms (2016) tested a version of the hypothesized CCSR model with an ethnically diverse sample of college students, rather than adolescents which was intended by the CCSR model. Overall, Farruggia and colleagues found some support for the hypothesized model, but some of their findings did not support the model. For example, they found a weak relationship between academic perseverance and academic performance and no relationship between learning strategies and academic performance.

Farruggia and colleagues (2016) also tested how the model differed by race/ethnicity and found support for the notion that the relationships among non-cognitive factors differ by race/ethnicity. For instance, the relationship between academic perseverance and academic performance was non-significant for Latino and African American students but significant for 
Asian and White students. This is especially important given the lack of studies examining subgroup differences (e.g., socioeconomic status [SES], race/ethnicity) in non-cognitive factors (Farrington et al., 2012). Youth growing up in low SES backgrounds or in marginalized communities may experience non-cognitive factors differently and have differential impacts of non-cognitive factors on academic performance (Chavez \& Guido-DiBrito, 1999; Deutsch, 2008; Phinney \& Rosenthal, 1992). Thus, it is important to not only examine the CCSR model but also examine how the CCSR model performs across different groups of students.

The findings by Farruggia and colleagues were likely impacted by several of their methodological decisions. For example, their population of interest was college students, and the hypothesized model was created with adolescent students in mind. Furthermore, learning strategies was measured as time management, which only accounts for a small portion of the skills related to learning strategies. Moreover, they did not have measures for all of the noncognitive factors in the hypothesized model. The current study uses different measures for all of the non-cognitive factors and uses a largely Hispanic and low-income group of high school students.

\section{The Current Study}

Further empirical testing is needed to determine the validity of the CCSR model developed by Farrington and colleagues, to consider the interactions across variables, and to isolate if any factors are more important than others for students' success. Furthermore, it is important to test this model among specific populations to understand for whom the relationships exist. Therefore, this study utilizes a majority-minority population and also examines group differences related to grade level, receipt of free/reduced priced lunch (FRPL), English Language Learners, parental education, and race/ethnicity to test the CCSR model of non-cognitive factors. 


\section{Methods}

This study utilized a survey of freshmen and seniors at high schools in a predominantly Hispanic and low-income district, as well as district data such as their previous GPA and GPA at the end of the year, to test the CCSR model of non-cognitive factors.

\section{Participants}

Survey participants included two cohorts-all freshmen and all seniors-from five high schools in a primarily Hispanic (85\%) and low-income (80\%) southern California school district. The five high schools serve 1,567 freshmen and 1,486 seniors. Students were excluded from participation if they did not speak English, if a disability precluded them from taking the surveys, or if they did not consent to taking the surveys. Demographics for the entire sample, as well as for freshmen and seniors separately, are provided in Table 1.

Table 1. Demographics of the entire sample, freshmen, and seniors

\begin{tabular}{lrrrrrr}
\hline & \multicolumn{2}{c}{$\begin{array}{c}\text { Freshmen } \\
n=1232\end{array}$} & \multicolumn{2}{c}{$\begin{array}{c}\text { Seniors } \\
n=997\end{array}$} & \multicolumn{3}{c}{$\begin{array}{c}\text { Full Sample } \\
n=2229\end{array}$} \\
\hline Gender & $n$ & $\%$ & $n$ & $\%$ & $n$ & $\%$ \\
$\quad$ Female & & & & & & \\
$\quad$ Male & 612 & 49.7 & 531 & 53.3 & 1143 & 51.3 \\
Race/Ethnicity & 620 & 50.3 & 466 & 46.7 & 1086 & 48.7 \\
$\quad$ Hispanic & & & & & & \\
Asian & 1057 & 86.0 & 815 & 81.9 & 1872 & 84.2 \\
$\quad$ Black & 55 & 4.5 & 80 & 8.0 & 135 & 6.1 \\
$\quad$ White & 65 & 5.3 & 53 & 5.3 & 118 & 5.3 \\
FRPL & 52 & 4.2 & 47 & 4.7 & 99 & 4.5 \\
$\quad$ Yes & & & & & & \\
$\quad$ No & 986 & 80.0 & 798 & 80.0 & 1784 & 80.0 \\
English Language Learners & 246 & 20.0 & 199 & 20.0 & 445 & 20.0 \\
$\quad$ EO & & & & & & \\
$\quad$ RFEP & 433 & 35.1 & 342 & 34.3 & 775 & 34.8 \\
$\quad$ LEP & 533 & 43.3 & 569 & 57.1 & 1102 & 49.4 \\
Parent Education & 266 & 21.6 & 86 & 8.6 & 352 & 15.8 \\
$\quad$ Less than high school & & & & & & \\
$\quad$ High school/GED & 418 & 45.7 & 330 & 44.6 & 748 & 45.2 \\
$\quad$ & 314 & 34.4 & 240 & 32.4 & 554 & 33.5 \\
\hline
\end{tabular}




\begin{tabular}{lllllll} 
At least some college & 182 & 19.9 & 170 & 23.0 & 352 & 21.3 \\
\hline
\end{tabular}

\section{Measures}

A series of psychological, social, and academic measures were included as part of a larger evaluation within a school district. Due to the number of measures included in the original evaluation study (many not included in this study), longer scales were sometimes reduced to fewer items to avoid survey fatigue. Descriptive statistics for all measures are shown in Table 2.

Table 2. Descriptive statistics for all Measures $(n=2,229)$

\begin{tabular}{lllllllll}
\hline Correlations $^{\mathbf{a}}$ & $\mathbf{1}$ & $\mathbf{2}$ & $\mathbf{3}$ & $\mathbf{4}$ & $\mathbf{5}$ & $\mathbf{6}$ & $\mathbf{7}$ & \multicolumn{1}{l}{$\mathbf{8}$} \\
\hline 1. Growth Mindset & & .411 & .569 & .140 & .184 & .053 & .062 & .074 \\
2. Leadership & .411 & & .645 & .086 & .115 & .271 & .108 & .098 \\
3. Prosociality & .569 & .645 & & .107 & .085 & .289 & .114 & .126 \\
4. Grit-Perseverance & .140 & .086 & .107 & & .515 & -.096 & .059 & .079 \\
5. Self-Control & .184 & .114 & .085 & .515 & & -.079 & .120 & .122 \\
6. Goal-Setting & .053 & .271 & .289 & -.096 & -.079 & & .132 & .108 \\
7. Previous GPA & .062 & .108 & .114 & .059 & .120 & .132 & & .739 \\
8. Current GPA & .074 & .098 & .126 & .079 & .122 & .108 & .739 & \\
\hline $\mathrm{M}$ & 3.54 & 3.82 & 3.60 & 3.26 & 3.51 & 3.35 & 2.84 & 2.83 \\
$\mathrm{SD}$ & .83 & .73 & .72 & 1.02 & .94 & .52 & .87 & .96 \\
$\alpha$ & .55 & .80 & .74 & .80 & .68 & .54 & N/A & N/A \\
\hline
\end{tabular}

${ }^{a}$ correlation values above .037 are $\mathrm{p}<.05$; above .052 are $\mathrm{p}<.01$; above .070 are $\mathrm{p}<.001$

Academic mindsets were measured using three of the four items of the Entity Self-Beliefs subscale of the Self-Theory version of the Implicit Theories of Intelligence Scale, otherwise known as growth mindset (De Castella \& Byrne, 2015). Two scales were used to measure social skills: leadership and prosociality. Leadership was measured with the eight-item leadership competence sub-scale of the Sociopolitical Control Scale for Youth (SPCS-Y; Peterson et al., 2001) which measures youth's perceptions of their skill at organizing a group of people.

Prosociality was created by the evaluation team to measure students' willingness to help and give back to their family and community and had eight items. Two scales were used to measure academic perseverance: grit-perseverance and self-control. Academic perseverance was 
measured using the Perseverance of Effort subscale of the Short Grit Scale (Duckworth \& Quinn, 2009). Self-control was measured using six items of the short version of the Self-Control Scale (Tangney, Baumeister, \& Boone, 2004) which measures youth's abilities to control thoughts, emotions, impulses, and performance. Lastly, learning strategies was measured with goal-setting behaviors, a 12-item scale developed for use by the evaluation team.

Students' academic performance data and demographic data were collected from the school district. Academic performance data included GPA: (a) previous GPA was defined as cumulative middle school (i.e., 6-8 grade) GPA for freshmen and 9 ${ }^{\text {th }}$ grade GPA for seniors and (b) current GPA was defined as 9 ${ }^{\text {th }}$ grade GPA for freshmen and cumulative high school (i.e., 9.12. grade) for seniors. No academic behaviors data was collected. Initially, the research team considered collecting attendance data from the district; however, average attendance at the five high schools was around $90 \%$ and therefore would provide little variability as a variable in the model. Demographic data collected from the school district included: gender, FRPL, English Language Learners, parents' highest education level, and race/ethnicity.

\section{Procedures}

Surveys were administered to all freshmen in Fall 2015 at the beginning of their freshman year of high school and to all seniors in Spring 2016 in the month prior to graduating high school. A member of the evaluation team was on-site for all data collection to inform participants about the nature of the study, answer any questions they may have regarding the surveys or the study, and to ensure consistency and proper survey administration. The district provided student demographic and academic data for all freshmen and seniors at the five participating high schools in Summer 2016.

\section{Analytic Procedures}


All analyses were conducted using the lavaan package in R (Rosseel, 2012). Robust maximum likelihood estimation was used due to violations of multivariate normality. The analytic approach involved three steps. First, the psychometric properties of all five scales were evaluated using confirmatory factor analysis (CFA). Second, once support of the factor structure was established, a structural equation model (SEM) was performed to test the hypothesized model of relationships among the non-cognitive factors and with academic performance (Farrington et al., 2012). Third, once the structural model was established, several multi-group SEMs were performed to test any differences between freshmen and seniors, students with low and high SES, and between students of different race/ethnicities in the hypothesized model.

All CFAs and SEM models were evaluated with several model fit indices. First, the measurement component was examined to determine whether they converged onto their respective factors. Items with factor loadings below .50 were removed from the model to minimize measurement error. A non-significant chi-square test, indicating differences between the actual and predicted covariance matrices, suggests a good approximation of the data (Ho, 2006). However, given the sensitivity of the chi-square test in relation to sample size, the chisquare to degrees of freedom ratio was also assessed, interpreting a ratio of less than five as acceptable (Bollen, 1989). Two incremental fit indices, the robust Comparative Fit Index (CFI) and robust Tucker Lewis Index (TLI; also known as the Non-Normed Fit Index or NNFI), were also used, with acceptable values above .90 and preferred values above .95 . Two absolute measures of fit, the robust Root Mean Square Error of Approximation (RMSEA) and Standardized Root Mean Square Residual (SRMR), were used, with values less than .08 acceptable and values less than .06 preferred. Lastly, modification indices were examined to 
determine whether model fit would improve with additional pathways added as well as to see if items would load strongly onto other factors, which would lead to removing that item.

Lastly, the final retained model was used to compare various groups across age (i.e., freshmen and seniors), SES (i.e., parental education and FRPL), and race/ethnicity (i.e., Hispanic and non-Hispanic students). Multiple group SEM was performed to test the SEM models across groups. First, configural invariance was tested to compare the measurement models to determine whether items are loading onto factors similarly across groups (Kline, 2015). If model fit was acceptable, weak invariance was tested to see whether factor loadings were similar across groups. The models for configural and weak invariance were tested using a chi-square difference test and comparing model fit indices. If model comparisons were statistically significant and differences in model fit indices greater than .001 , then variance at that step was assumed and the configural model was retained. If model comparisons were not statistically significant or differences in the model fit indices were less than or equal to .001, then invariance at that step was assumed and the weak model was retained. If weak invariance was obtained, then structural invariance was tested to see whether the regression pathways were similar across groups. Model comparisons were performed again for the weak compared to the structural invariance models. As discussed in the results section below, no models obtained structural invariance.

\section{Results}

\section{Confirmatory Factor Analyses}

Confirmatory factor analysis was performed on all items used in this study (see Table 3). The initial CFA resulted in poor model fit. Seven items (one prosocial, two self-control, and four goal-setting items) were removed due to poor factor loadings $(<.50)$ and an eighth item (prosocial) was also removed because it was the only remaining family-related prosociality item, 
leaving the prosociality construct to measure community-related prosociality only. The next CFA (CFA 2), with the eight items removed, improved in model fit but still had a relatively poor fit. Modification indices were examined at this point, and they suggested (a) that one leadership item should load onto multiple other factors and so this item was removed and (b) that three pairs of prosociality items and one pair of leadership items should be correlated and so these item error terms were correlated. The next CFA (CFA 3), with four item error correlations and one additional item removed, resulted in a good model fit. Finally, a fourth CFA was examined in which second-order latent factors of social skills and academic perseverance were added to the model; this model would allow testing the second-order latent factors in the structural model of the SEMs. This model resulted in a good model fit but had a slightly worse fit than the third CFA in which there were no second-order factors; however, the fourth CFA was retained for parsimony and for use with the SEM models. All items from CFA 4 loaded onto their respective factors with a standardized loading greater than .50 ; furthermore, both first-order latent factors loaded onto the second-order factors at a strength ranging from .699 to .806 . 
Table 3. CFA and SEM Model Fit Results

\begin{tabular}{|c|c|c|c|c|c|c|c|c|c|}
\hline \multicolumn{2}{|l|}{ Model } & $\chi^{2}$ & df & $\chi^{2} / \mathrm{df}$ & CFI & TLI & RMSEA & SRMR & $\chi^{2}$ diff \\
\hline \multicolumn{2}{|l|}{ CFA 1} & 5659.62 & 764 & 7.41 & .819 & .805 & .061 & .068 & \\
\hline \multicolumn{2}{|l|}{ CFA 2} & 2991.71 & 480 & 6.23 & .888 & .877 & .056 & .043 & \\
\hline \multicolumn{2}{|c|}{ CFA 3} & 1520.26 & 445 & 3.42 & .951 & .945 & .038 & .036 & \\
\hline \multicolumn{2}{|c|}{ CFA $4-2^{\text {nd }}$ order Factors } & 1583.43 & 450 & 3.52 & .948 & .942 & .039 & .043 & \\
\hline \multicolumn{2}{|c|}{ SEM } & 2100.48 & 480 & 4.38 & .925 & .917 & .045 & .100 & \\
\hline \multicolumn{10}{|c|}{ Multi-Group SEMs } \\
\hline \multirow{3}{*}{ 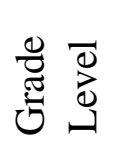 } & Configural & 2639.94 & 960 & 2.75 & .926 & .918 & .046 & .103 & \\
\hline & Weak & 2717.75 & 986 & 2.76 & .924 & .918 & .046 & .103 & $78.81(26) * * *$ \\
\hline & Structural & 2750.18 & 994 & 2.77 & .923 & .918 & .046 & .104 & $37.74(8) * * *$ \\
\hline \multirow{3}{*}{ 芯 } & Configural & 2656.30 & 1440 & 1.84 & .924 & .916 & .045 & .110 & \\
\hline & Weak & 2709.48 & 1492 & 1.82 & .924 & .920 & .045 & .111 & $45.76(52)$ \\
\hline & Structural & 2740.38 & 1508 & 1.82 & .924 & .920 & .044 & .112 & $32.02(16) * *$ \\
\hline \multirow{3}{*}{$\frac{\vec{\partial}}{\frac{\alpha}{I}}$} & Configural & 2661.22 & 960 & 2.77 & .923 & .916 & .046 & .102 & \\
\hline & Weak & 2694.63 & 986 & 2.73 & .923 & .918 & .045 & .103 & $27.81(26)$ \\
\hline & Structural & 2715.38 & 994 & 2.73 & .923 & .918 & .045 & .103 & $20.28(8) * *$ \\
\hline \multirow{3}{*}{ 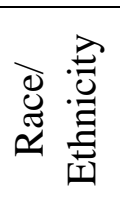 } & Configural & 3843.65 & 1920 & 2.00 & .916 & .908 & .048 & .104 & \\
\hline & Weak & 3936.77 & 1998 & 1.97 & .915 & .100 & .047 & .105 & $95.44(78)$ \\
\hline & Structural & 3978.71 & 2022 & 1.97 & .915 & .911 & .047 & .105 & $39.17(24) *$ \\
\hline
\end{tabular}

Note: LS = Learning Strategies, $S S=$ Social Skills 


\section{Group Differences}

Composite scores based on the final CFA model were created for all measures using simple mean composites. Descriptive statistics for all measures can be found in Table 2. Welch's t-tests and one-way ANOVAs were performed to compare scores on the non-cognitive factors across four demographics (see Table 4). Using a Bonferroni adjustment for alpha inflation, alpha levels would adjust from .05 to .0017 with 30 tests performed; analyses that are statistically significant after a Bonferroni correction are shown in bold. Overall, there were statistically significant differences across groups but effect sizes were small (i.e., Cohen's $d$ ranged from .00 to .43 and $\eta^{2}$ ranged from .00 to .08). Most differences occurred between freshmen and seniors, with freshmen displaying greater growth mindset and self-control but lower prosociality and goal-setting behaviors than seniors. Furthermore, English Language Learners reported lower growth mindset, leadership skills, perseverance, self-control, and goal-setting than students who only spoke English. Initially Fluent English Proficient and Re-designated Fluent English Proficient (IFEP/RFEP) students scored lower in leadership, perseverance, self-control, and goalsetting than both students who only spoke English and students in English language classes. Lastly, there were differences in non-cognitive factors across different ethnicities; for instance, Hispanic students scored lowest among their peers on leadership skills, prosociality, and goalsetting behaviors whereas Asian students scored lowest among their peers on growth mindset, perseverance, and self-control. 


\begin{tabular}{|c|c|c|c|c|c|c|c|}
\hline & \multirow[b]{2}{*}{$n$} & \multirow{2}{*}{$\begin{array}{c}\text { Academic } \\
\text { Mindsets } \\
\text { Growth Mindset }\end{array}$} & \multicolumn{2}{|c|}{ Social Skills } & \multicolumn{2}{|c|}{ Academic Perseverance } & \multirow{2}{*}{\begin{tabular}{|c|} 
Learning \\
Strategies \\
Goal-Setting
\end{tabular}} \\
\hline & & & Leadership & Prosociality & Grit - Perseverance & Self-Control & \\
\hline Grade Level & & $\begin{array}{l}t(\mathbf{1 9 0 2})=2.96 * * \\
d=.13\end{array}$ & $\begin{array}{l}t(1995)=1.00 \\
d=.00\end{array}$ & $\begin{array}{l}t(\mathbf{1 9 5 3})=\mathbf{4 . 5 3}^{* * *} \\
d=.20\end{array}$ & $\begin{array}{l}t(2115)=2.02 \\
d=.09\end{array}$ & $\begin{array}{l}t(\mathbf{2 0 0 8})=9.74 * * * \\
d=.43\end{array}$ & $\begin{array}{l}t(\mathbf{2 0 2 4})=4.28 * * * \\
d=.19\end{array}$ \\
\hline Freshmen & 1219 & $3.69(.92)$ & $3.79(.71)$ & $3.40(.74)$ & $3.34(.98)$ & $3.79(.87)$ & $3.31(.50)$ \\
\hline Seniors & 957 & $3.56(1.06)$ & $3.79(.76)$ & $3.56(.82)$ & $3.25(.96)$ & $3.41(.91)$ & $3.41(.54)$ \\
\hline English Languag & & $\begin{array}{l}F(2,941)=3.14^{*} \\
\eta^{2}=.01\end{array}$ & $\begin{array}{l}F(2,908)=5.26^{* *} \\
\eta^{2}=.01\end{array}$ & $\begin{array}{l}F(2,910)=1.87 \\
\eta^{2}=.00\end{array}$ & $\begin{array}{l}\boldsymbol{F}(\mathbf{2}, \mathbf{9 5 8})=10.47 * * * \\
\eta^{2}=.02\end{array}$ & $\begin{array}{l}F(2,918)=6.25^{* *} \\
\eta^{2}=.01\end{array}$ & $\begin{array}{l}F(2,901)=6.39 * * \\
\eta^{2}=.01\end{array}$ \\
\hline English Only & 746 & $3.57(1.00)$ & $3.84(.74)$ & $3.52(.81)$ & $3.36(1.01)$ & $3.67(.92)$ & $3.38(.51)$ \\
\hline IFEP/RFEP & 991 & $3.66(.99)$ & $3.79(.71)$ & $3.46(.75)$ & $3.32(.96)$ & $3.65(.89)$ & $3.36(.51)$ \\
\hline $\begin{array}{l}\text { English } \\
\text { Learners }\end{array}$ & 419 & $3.72(.94)$ & $3.68(.78)$ & $3.43(.80)$ & $3.09(.92)$ & $3.46(.93)$ & $3.26(.58)$ \\
\hline Parent Educatio & & $\begin{array}{l}F(2,835)=1.30 \\
\eta^{2}=.00\end{array}$ & $\begin{array}{l}F(2,866)=3.62 * \\
\eta^{2}=.01\end{array}$ & $\begin{array}{l}F(2,837)=1.99 \\
\eta^{2}=.00\end{array}$ & $\begin{array}{l}F(2,855)=1.52 \\
\eta^{2}=.00\end{array}$ & $\begin{array}{l}F(2,854)=0.47 \\
\eta^{2}=.00\end{array}$ & $\begin{array}{l}F(2,910)=2.27 \\
\eta^{2}=.01\end{array}$ \\
\hline$<\mathrm{HS}$ & 721 & $3.67(.96)$ & $3.75(.71)$ & $3.45(.77)$ & $3.27(.92)$ & $3.62(.90)$ & $3.33(.54)$ \\
\hline HS/GED & 542 & $3.62(.99)$ & $3.76(.75)$ & $3.43(.77)$ & $3.30(1.02)$ & $3.65(.92)$ & $3.36(.49)$ \\
\hline $\begin{array}{l}\text { Some } \\
\text { College > }\end{array}$ & 337 & $3.57(1.09)$ & $3.88(.73)$ & $3.55(.86)$ & $3.38(1.02)$ & $3.67(.95)$ & $3.40(.50)$ \\
\hline FRPL & & $\begin{array}{l}t(664)=1.09 \\
d=.06\end{array}$ & $\begin{array}{l}t(677)=1.82 \\
d=.11\end{array}$ & $\begin{array}{l}t(651)=1.26 \\
d=.08\end{array}$ & $\begin{array}{l}t(677)=0.47 \\
d=.02\end{array}$ & $\begin{array}{l}t(694)=2.02 * \\
d=.21\end{array}$ & $\begin{array}{l}t(710)=1.76 \\
d=.10\end{array}$ \\
\hline Yes & 1724 & $3.65(.99)$ & $3.77(.74)$ & $3.46(.78)$ & $3.30(.98)$ & $3.51(.92)$ & $3.34(.53)$ \\
\hline No & 432 & $3.59(.99)$ & $3.85(.72)$ & $3.52(.79)$ & $3.32(.97)$ & $3.70(.87)$ & $3.39(.49)$ \\
\hline Race/Ethnicity & & $\begin{array}{l}F(3,200)=0.28 \\
\eta^{2}=.00\end{array}$ & $\begin{array}{l}\boldsymbol{F}(\mathbf{3}, \mathbf{2 0 7})=\mathbf{5 . 5 5} * * \\
\eta^{2}=.07\end{array}$ & $\begin{array}{l}\boldsymbol{F}(\mathbf{3}, \mathbf{2 0 1})=\mathbf{5 . 3 3}^{* *} \\
\eta^{2}=.07\end{array}$ & $\begin{array}{l}\boldsymbol{F ( 3 , \mathbf { 2 0 7 } ) = \mathbf { 5 . 8 8 } * * *} \\
\eta^{2}=.08\end{array}$ & $\begin{array}{l}F(3,204)=0.76 \\
\eta^{2}=.01\end{array}$ & $\begin{array}{l}F(3,213)=3.50^{*} \\
\eta^{2}=.05\end{array}$ \\
\hline Hispanic & 1814 & $3.65(.97)$ & $3.77(.74)$ & $3.45(.77)$ & $3.29(.97)$ & $3.63(.91)$ & $3.34(.52)$ \\
\hline Asian & 134 & $3.57(1.07)$ & $3.80(.67)$ & $3.54(.79)$ & $3.08(.91)$ & $3.54(.77)$ & $3.44(.50)$ \\
\hline Black & 108 & $3.62(1.17)$ & $4.02(.69)$ & $3.72(.79)$ & $3.59(1.03)$ & $3.64(1.01)$ & $3.46(.51)$ \\
\hline White & 96 & $3.61(.98)$ & $3.91(.66)$ & $3.62(.83)$ & $3.39(.99)$ & $3.57(.90)$ & $3.33(.48)$ \\
\hline
\end{tabular}

Note: For each group, standard deviations are shown in parentheses after the means. IFEP/RFEP = Initially/Redesignated Fluent English Proficient. FRPL $=$ Free or Reduced Priced Lunch. Though a Bonferroni correction was not performed, the alpha level would adjust from .05 to .0017.

Therefore, only bolded analyses would be retained with a Bonferroni correction. 


\section{Structural Equation Models}

An SEM model was performed testing the hypothesized model of how non-cognitive factors relate to academic performance. The measurement model was based on the fourth CFA in which there were two second-order factors of social skills (leadership and prosociality) and academic perseverance (grit-perseverance and self-control) while the structural model was based on the hypothesized model in Figure 1. This model resulted in a good model fit (see Table 3). Modification indices were examined, and they suggested correlating learning strategies and social skills, which improved model fit significantly, $\chi^{2}(479)=1704.68, \chi^{2} / \mathrm{df}$ ratio $=3.56, \mathrm{CFI}=$ $.943, \mathrm{TLI}=.937, \mathrm{RMSEA}=.039, \mathrm{SRMR}=.043$, resulting in a latent correlation between learning strategies and social skills of .625. However, given the purpose of this study to examine the CCSR model of non-cognitive factors' relationships with academic performance, the SEM Hypothesized model was retained for further analysis. See Figure 2 for the final SEM model and the first row of Table 5 for the regression pathways.

Overall, growth mindset was the non-cognitive factor most strongly related to current GPA $(\beta=.197, p<.001)$. Social skills $(\beta=.097, p=.001)$ and learning strategies $(\beta=.072, p=$ $.002)$ were also related to GPA, albeit at a weaker strength. Academic perseverance ( $\beta=.006, p$ $=.860)$ was not related to current GPA beyond the other non-cognitive factors. Furthermore, growth mindset was related to all three other non-cognitive factors, including social skills ( $\beta=$ $.145, p<.001)$, academic perseverance $(\beta=.334, p<.001)$, and learning strategies $(\beta=.108, p<$ .001). However, learning strategies was not significantly related to academic perseverance above and beyond growth mindset $(\beta=.057, p<.124)$. This model predicted $6.3 \%$ of the variance in current GPA. 


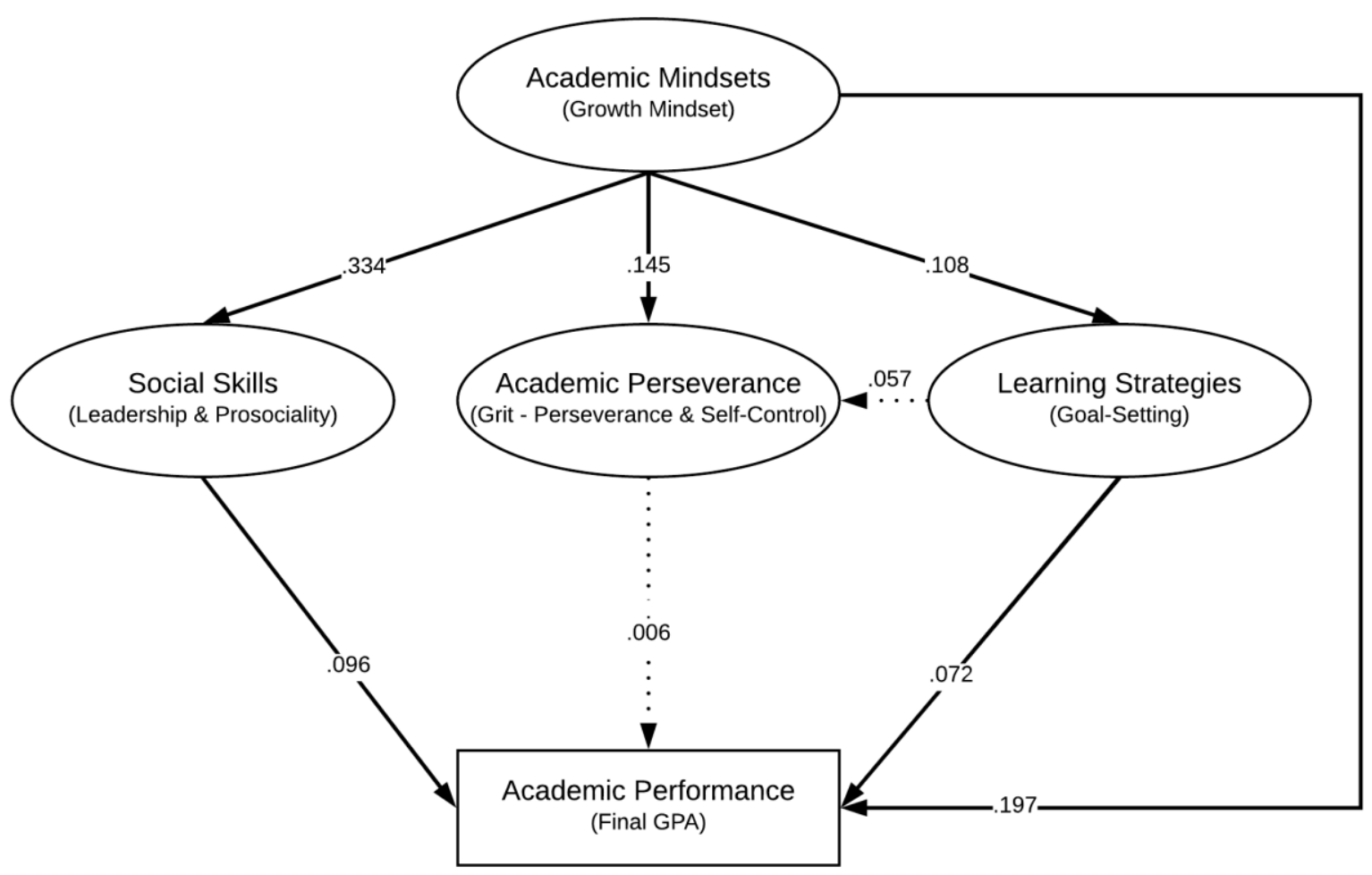

Figure 2. Final SEM model

Note: The measurement model (i.e., individual items and their error terms), first-order factors for social skills and academic perseverance, and latent error terms are not shown for sake of brevity. Solid lines signify statistically significant pathways while dotted lines signify statistically nonsignificant pathways. Strength of pathways is also indicated by width of the solid lines.

A third SEM model was examined in which previous GPA was added to the hypothesized model to determine how non-cognitive factors predicted current GPA after controlling for previous GPA. This resulted in a good model fit, $\chi^{2}(512)=2126.18, \chi^{2} / \mathrm{df}$ ratio $=4.15, \mathrm{CFI}=$ $.923, \mathrm{TLI}=.916, \mathrm{RMSEA}=.045, \mathrm{SRMR}=.098$. In this model, previous GPA significantly predicted academic mindsets $(\beta=.183, p<.001)$. Furthermore, previous GPA was the largest predictor of current GPA $(\beta=.722, p<.001)$ followed by academic mindsets $(\beta=.067, p=$ .001). None of the other three non-cognitive factors were significantly related to current GPA, and learning strategies continued not to be related to academic perseverance. This model 
predicted $55.3 \%$ of the variance in current GPA meaning previous GPA explained an additional $49 \%$ of the variance in current GPA over and beyond the non-cognitive factors.

\section{Multi-group SEMs}

Multi-group SEMs were used to compare models by grade level, parent education, and FRPL (see Table 3). English Language Learner status was not included due to large standard errors for the group of English Learners (LEP) (i.e., standard errors for regression pathways exceeding .30). As seen below, structural invariance was not accepted for all types of groups analyzed. Therefore, the structural pathway differences among the types of groups shown in Table 5 are based on the results of the weak invariance models.

Grade level. Configural invariance was accepted. There was evidence of weak (or metric) variance $\left(\Delta \chi_{2}[26]=78.81, p<.001\right)$; however, differences between model fit indices were miniscule (e.g., $\Delta \mathrm{CFI}=.001$ ) and comparisons of standardized factor loadings suggested that the only differences were that factor loadings were for the most part stronger for seniors than for freshmen. This finding is intuitive given that youth increase in their ability to respond to surveys as they get older (Hoeschler, Balestra, \& Backes-Gellner, 2018). For these reasons, weak invariance was accepted, and structural invariance (i.e., whether the structural model is the same across freshmen and seniors) was tested. Model comparison between the weak and structural invariance models was statistically significant $(\Delta \chi 2[8]=37.74, p<.001)$ though differences between model fit indices were miniscule (e.g., $\Delta \mathrm{CFI}=.001)$. Therefore, structural invariance was not accepted, and differences between the structural models of freshmen and seniors were compared. The largest difference between freshmen and seniors was that the path from social skills to GPA was significant for seniors but not for freshmen, whereas the pathway from academic mindsets to learning strategies was significant for freshmen but not for seniors. 
Furthermore, academic perseverance was weakly negatively related to GPA for seniors but not significantly related to GPA for freshmen.

Parent Education. Both configural and weak invariance were accepted. Model comparison between the weak and structural models was statistically significant $(\Delta \chi[16]=$ $32.02, p=.010$ ); however, differences between model fit indices were small (e.g., $\triangle$ RMSEA = .001). Most of the differences between the groups reflected that more pathways were significant for students whose parents attended at least some college than for students whose parents did not graduate high school and students whose parents did graduate high school.

FRPL. Both configural and weak invariance were accepted. Model comparison between the weak and structural was statistically significant $(\Delta \chi[8]=20.28, p=.012)$; however, there were no differences between model fit indices (e.g., $\Delta \mathrm{CFI}=.000$ ). The largest differences between groups were that the paths from social skills and learning strategies to GPA as well as from academic mindsets to learning strategies were statistically significant for students receiving FRPL but not statistically significant for students not receiving FRPL

Race/Ethnicity. Given the small sample sizes of Asian $(n=132)$, Black $(n=105)$, and White $(n=90)$ students with full data, Hispanic and non-Hispanic youth were instead compared. Both configural and weak invariance were accepted. Model comparison between the weak and structural models was statistically significant $\left(\Delta \chi^{2}[24]=39.17, p=.026\right)$; however, there were no differences between model fit indices (e.g., $\Delta \mathrm{CFI}=.000$ and $\triangle \mathrm{RMSEA}=.000$ ). 
Table 5. Group Differences in the Structural Models for the Multi-Group SEM Models

\begin{tabular}{|c|c|c|c|c|c|c|c|c|c|c|c|}
\hline \multicolumn{3}{|c|}{ Outcome: } & \multicolumn{5}{|c|}{ GPA } & \multicolumn{2}{|c|}{ Perseverance } & \multirow{2}{*}{$\begin{array}{c}\text { Social } \\
\text { Skills } \\
\text { Mindsets }\end{array}$} & \multirow{2}{*}{$\begin{array}{c}\text { Learning } \\
\text { Strategies } \\
\text { Mindsets }\end{array}$} \\
\hline \multicolumn{2}{|c|}{ Predictor: } & $n$ & $R^{2}$ & Mindsets & $\begin{array}{l}\text { Social } \\
\text { Skills }\end{array}$ & $\begin{array}{c}\text { Per- } \\
\text { severance }\end{array}$ & $\begin{array}{l}\text { Learning } \\
\text { Strategies }\end{array}$ & Mindsets & $\begin{array}{l}\text { Learning } \\
\text { Strategies }\end{array}$ & & \\
\hline \multicolumn{2}{|c|}{ Overall } & 2055 & .063 & $.197 * * *$ & $.096 * *$ & .006 & $.072 * *$ & $.334 * * *$ & .057 & $.145 * * *$ & $.108 * * *$ \\
\hline \multirow{4}{*}{$\frac{0}{\widetilde{T}}$} & Freshme & 1120 & .084 & $.186 * * *$ & .014 & .095 & $.115^{* *}$ & $.454 * * *$ & .073 & $.152 * *$ & $.146^{* * * *}$ \\
\hline & & & & $(.07)$ & $(.09)$ & $(.11)$ & $(.06)$ & $(.03)$ & $(.04)$ & $(.04)$ & (.04) \\
\hline & Senior & 935 & .071 & $.162 * * *$ & $.181 * * *$ & $-.110 *$ & $.031 *$ & $.235 * * *$ & .028 & $.141 * *$ & .078 \\
\hline & & & & $(.04)$ & $(.04)$ & $(.07)$ & $(.03)$ & $(.04)$ & $(.03)$ & $(.04)$ & $(.04)$ \\
\hline \multirow{6}{*}{ 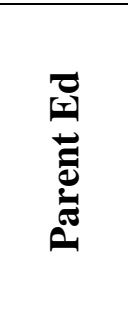 } & $<\mathrm{HS}$ & 692 & .084 & $.206 * * *$ & .047 & .110 & .057 & $.393 * * *$ & .038 & .122 & .071 \\
\hline & & & & $(.07)$ & $(.08)$ & $(.12)$ & $(.05)$ & $(.05)$ & $(.04)$ & $(.05)$ & $(.05)$ \\
\hline & HS & 513 & .068 & $.203 * * *$ & $.120 *$ & .024 & .039 & $.243 * *$ & $.193 * *$ & .118 & .093 \\
\hline & & & & $(.07)$ & $(.08)$ & $(.14)$ & $(.06)$ & $(.04)$ & $(.05)$ & $(.05)$ & $(.05)$ \\
\hline & $>\mathrm{HS}$ & 323 & .116 & $.217 * *$ & $.164 *$ & $-.195 * *$ & $.140 *$ & $.332 * * *$ & .155 & $.271 * * *$ & $.172 * *$ \\
\hline & & & & $(.10)$ & $(.10)$ & $(.12)$ & $(.09)$ & $(.06)$ & $(.06)$ & $(.06)$ & $(.06)$ \\
\hline \multirow{4}{*}{$\vec{a}$} & FRPL & 1638 & .061 & $.143 * * *$ & $.107 * *$ & .070 & $.086^{* *}$ & $.351 * * *$ & .040 & $.137 * *$ & $.120 * * *$ \\
\hline & & & & $(.04)$ & $(.05)$ & $(.07)$ & $(.04)$ & $(.03)$ & $(.03)$ & $(.04)$ & $(.03)$ \\
\hline & No FRPL & 417 & .125 & $.354 * * *$ & .050 & $-.140 *$ & .040 & $.287 * * *$ & .139 & $.173^{*}$ & .053 \\
\hline & & & & $(.08)$ & $(.09)$ & $(.12)$ & $(.06)$ & $(.05)$ & $(.06)$ & $(.06)$ & $(.06)$ \\
\hline \multirow{4}{*}{ ¿ } & Hispanic & 1725 & .063 & $.147 * * *$ & $.109 * * *$ & .068 & $.090 * * *$ & $.379 * * *$ & .021 & $.128 * *$ & $.102 * *$ \\
\hline & & & & $(.04)$ & $(.04)$ & $(.07)$ & $(.03)$ & $(.03)$ & $(.03)$ & $(.04)$ & $(.03)$ \\
\hline & Non- & 330 & .105 & $.324 * * *$ & .012 & -.118 & .007 & $.178^{*}$ & $.227 *$ & $.193 *$ & .119 \\
\hline & Hispanic & & & $(.09)$ & $(.12)$ & $(.13)$ & $(.10)$ & $(.07)$ & $(.07)$ & $(.06)$ & $(.07)$ \\
\hline
\end{tabular}

Note: $\mathrm{R}^{2}$ values are shown in the first column under GPA. Standardized coefficients and (standard errors) are shown for the remaining columns. 


\section{Discussion}

This study aimed to test the model put forth by the researchers at CCSR on how noncognitive factors relate to academic performance among adolescents. Building from the Developmental Systems Theory (DST) framework, multiple analyses using a diverse youth population and a variety of measures were conducted to examine the validity of the UCCR hypothesized model. It is important to test the model in as many situations as possible to refute the null hypothesis (i.e., that non-cognitive factors do not significantly impact academic performance). For this reason, this study included tests of multiple group differences with an understudied population.

The overall variance explained by the model was $6.3 \%$. This small effect size is unsurprising given the literature indicating that large sample sizes are needed to detect small to moderate effects of non-cognitive factors (Jones \& Bouffard, 2012; Sisk et al., 2018; Yeager et al., 2018). This albeit small effect is meaningful in that small changes in academic performance can have large effects on later life success (e.g., college and career attainment and success, physical and mental health; Cutler \& Lleras-Muney, 2006; Day \& Newburger, 2002) and small interventions can have meaningful changes for students (e.g., growth mindset and academic performance; Yeager et al., 2018; Yeager \& Walton, 2011). Moreover, these small effect sizes can sometimes be the tipping point for students to find pathways to success, particularly among traditionally marginalized students.

Overall, we found partial support for the pathways within the UCCR hypothesized model; academic mindsets, social skills, and learning strategies were significant predictors of academic performance. We failed to find support for academic perseverance predicting academic performance in the context of the other, statistically significant non-cognitive factors, which is in 
line with other studies examining the association between academic perseverance and academic outcomes (Credé et al., 2016; Farrugia et al., 2016). The pathways from academic mindsets to each of the non-cognitive factors (i.e., social skills, academic perseverance, and learning strategies) were statistically significant. Academic mindsets stands out as a particularly important predictor of academic performance and each of the other non-cognitive factors. Furthermore, academic mindsets comprised the only consistently significant factor for students across backgrounds. Together, these results suggest that academic mindsets deserve greater attention from researchers and practitioners.

The CCSR model also describes a feedback loop from academic performance to future academic mindsets, such that non-cognitive skills and academic performance both affect and are affected by one another. Additionally, student GPA is often highly contingent upon previous GPA the year or even multiple years prior. To account for this feedback loop, a second model was tested in which previous GPA was included as a predictor of both academic mindsets and current GPA. In line with other studies, previous academic performance explained roughly $50 \%$ of the variance in current academic performance. Furthermore, by adding previous GPA to the model, the pathways from social skills, academic perseverance, and learning strategies to final GPA became non-significant. These results support the notion that GPA consists of both cognitive and non-cognitive factors and that there is a cyclical nature between academic performance and non-cognitive outcomes such that they both mutually influence on another. These results support the notion that some of the variance in GPA consists of non-cognitive factors such captures both cognitive and non-cognitive factors, and therefore previous GPA may be taking out some of the variance that can be uniquely explained by the non-cognitive factors. 
This finding suggests that there may be a cyclical nature between GPA and non-cognitive outcomes such that they both mutually influence one another.

As mentioned earlier, little research to date has closely examined group difference factors of non-cognitive skills in relation to academic performance. Examining these group differences - particularly across SES and race/ethnicity — is especially important given the research on children from low SES and marginalized communities have a more difficult time integrating their identity in the context of a dominant white, middle-class culture (Chavez \& Guido-DiBrito, 1999; Deutsch, 2008; Phinney \& Rosenthal, 1992). One meta-analysis on grit and another on growth mindset have highlighted the point that more research is needed (Credé et al., 2016; Sisk et al., 2018). Group comparisons have the potential to pinpoint the mechanisms underlying differences found. To understand group differences more fully, our analyses included grade, parental education level, income level, and race/ethnicity. While there is a dearth of research to draw from to develop explanations for those differences, we discuss a few potential implications.

First, when examining group differences by grade, we found that the pathways from the non-cognitive factors to final GPA were stronger for seniors than freshmen, and the pathways from growth mindset to the other non-cognitive factors were stronger for freshmen than seniors. Given that GPA was a cumulative high school measure and freshmen only had a year in high school at this point, this suggests that cumulative GPA is not simply intelligence or academic performance but also comprises non-cognitive factors. Furthermore, we found support for a cyclical relationship between non-cognitive factors and academic performance, which is reflected in the CCSR model. In fact, when we controlled for previous GPA, many of these relationships between the non-cognitive factors and GPA disappeared, further suggesting that 
GPA is a reflection of non-cognitive factors due to shared variance. However, it could also mean that more non-cognitive factors are important at later adolescence when students are beginning to think about their post-high school prospects such as college (Nagaoka, Farrington, Ehrlich, \& Heath, 2015).

We also examined two proxies of socioeconomic status: parent education and FRPL. For parent education, more non-cognitive factors were related to GPA for students whose parents attended at least some college. The R-squared value was also larger for those students whose parents attended at least some college. Only mindsets predict GPA and perseverance for students with parents who have less than a high school degree. Social skills and learning strategies were more important predictors of GPA for students who receive FRPL, but mindsets was a strong predictor of GPA for students who did not receive FRPL. The R-squared was much stronger for students who did not receive FRPL. While we see a similar pattern in effect size for the two indicators of SES, there were more significant pathways for the lower SES students when using FRPL status as an indicator. These somewhat discrepant findings may provide some clarification for why there have been mixed findings in the literature taking into account SES in the school context; for instance, some studies have shown students from lower SES have fewer internal and external assets to begin with yet show greater growth in developing those assets than their more affluent peers (Thompson, Corsello, McReynolds, \& Conklin-Powers, 2013). However, these findings are also limited due to the smaller sample size of students who did not qualify for FRPL. Further research on low-SES youth could illuminate the reason for the differences found.

Lastly, when examining group differences by race/ethnicity, there were differences in the relationship between non-cognitive factors and GPA for Hispanic students compared to other ethnic and racial identities; the pathways from mindsets to learning strategies and social skills to 
GPA were particularly important for Hispanic adolescents compared to other racial/ethnic identities. These differences indicate that various non-cognitive factors may have differing impacts on students with different backgrounds. Further study is warranted to inform a more nuanced and evidence-based approach for practitioners to facilitate the development of noncognitive factors among diverse student populations. On the other hand, mindsets were consistently predictive of GPA regardless of racial/ethnic identity; therefore, mindsets may be an important construct for practitioners to target more universally. Further research with larger samples of a wide range of subgroups is needed due to the great differences in sample sizes in this study (i.e., large Hispanic population and smaller Asian, Black, and White populations) before strong conclusions can be made.

Surprisingly, there was a significant negative pathway from academic perseverance to GPA for senior students, highly educated parents of students, and Asian students. This suggests that perseverance plays an important role in predicting GPA after controlling for other noncognitive factors; specifically, although perseverance is positively correlated with GPA, the part of perseverance that is independent of the other non-cognitive factors is negatively correlated with GPA. This could also be interpreted that students with lower scores on non-cognitive factors and lower GPA need higher perseverance to improve GPA levels.

Taken together, these findings regarding group differences indicate there are some pathways that are stronger for some groups than others. This study provides the basis to build future research and practice on the pathways among non-cognitive factors and GPA with group differences accounted for. Future directions of research examining group differences may want to consider (a) do non-cognitive factors impact minority students in similar ways to majority 
students? and (b) are the measures of non-cognitive factors culturally sensitive to minority populations?

\section{Limitations}

Several limitations warrant mention. First, a major limitation of this study was the absence of academic behaviors. The literature and UCCR model suggest that academic behaviors serve as a mediator from those non-cognitive factors to academic performance. Therefore, by not including academic behaviors, that indirect relationship could not be detected for each of the non-cognitive factors and academic performance and a direct relationship was tested instead.

Future studies should include academic behaviors to identify their role with non-cognitive factors and academic performance.

Second, the study made use of existing district survey data. Therefore, constructs included in the study were based on data availability; this is why academic behaviors were unable to be accounted for in our analyses. Many of the measures employed in the study were reduced due to concern over the length of the survey causing survey fatigue with participants. Furthermore, our measure of social skills does not completely align with the definition provided by Farrington and colleagues (2012). Each of the factors are multidimensional; therefore, future studies should consider measures that account for all the dimensions. Future studies should examine the effectiveness of the model with other operationalizations and measurements of the different non-cognitive factors.

Third, this study was cross-sectional at the level of the non-cognitive factors; students were only surveyed once regarding non-cognitive factors, and thus causality cannot be ascertained within the non-cognitive factors. However, academic performance was collected both before and after collection of the non-cognitive data collection. Furthermore, future waves of 
data collection, planned with the freshman cohort, will allow for future longitudinal studies to examine growth in non-cognitive factors and the relationship between growth in non-cognitive factors and changes in academic performance.

Last, this study examined a predominantly low-income and Hispanic population. Although this population is understudied in terms of non-cognitive factors, this restricts comparisons to higher-income and non-Hispanic populations. Examining the CCSR model in a sample more representative of the United States adolescent population would allow for stronger group comparisons.

\section{Conclusion}

Group differences like culture may be important to consider when thinking about for whom these relationships among non-cognitive factors and academic performance matter. As schools implement non-cognitive accountability measures as part of the Every Student Succeeds Act (ESSA), we need to be sure we fully understand individual and group differences and the implications and impact of non-cognitive factors on students' academic performance. For practitioners to be able to apply these findings, it is important to study these factors together, with different measures and populations. It is also important to understand their interactions and to identify which non-cognitive factor performs the best while considering the other factors. Our findings indicate growth mindset as particularly important with this population because it not only impacts GPA but the three other non-cognitive factors as well.

While the findings from this study indicate non-cognitive factors contribute to academic performance above and beyond previous GPA, we need to be careful in our conclusions. Even including previous GPA in the model, there is a lot of variance in academic performance, with approximately $44 \%$, not accounted for. We need to better understand the missing factors that 
contribute to academic performance to best support student success. Still, this study demonstrates that non-cognitive factors have a role to play in students' academic success and finds that group difference factors are associated with the nature and strength of those relationships. Therefore, practitioners should keep group differences in mind as they use non-cognitive factors as a strategy to achieve academic success for their students. 


\section{References}

Aronson, J., Fried, C.B., and Good, C. (2002). Reducing the effects of stereotype threat on African American college students by shaping theories of intelligence. Journal of Experimental Social Psychology, 38, 113-125.

Bandura, A. (1977). Social Learning Theory. Morristown, NJ: General Learning Press.

Bandura, A. (1986). Social foundations of thought and action: A social cognitive theory. Englewood Cliffs, NJ: Prentice Hall.

Bean, R. A., Bush, K. R., McKenry, P. C., \& Wilson, S. M. (2003). The impact of parental support, behavioral control, and psychological control on the academic achievement and self-esteem of African American and European American adolescents. Journal of Adolescent Research, 18(5), 523-541.

Beer, R. D. (2000). Dynamical approaches to cognitive science. Trends in Cognitive Sciences, 4(3), 91-99.

Bembenutty, H. \& Karabenick, S. A. (1998). Academic delay of gratification. Learning and Individual Differences, 10(4), 329-346.

Bollen, K. A. (1989). Structural equations with latent variables. New York: John Wiley \& Sons.

CASEL (n.d.). What is SEL? https://casel.org/what-is-sel/

Chavez, A. F., \& Guido-DiBrito, F. (1999). Racial and ethnic identity and development. New Directions for Adult and Continuing Education, 1999 (84), 39-47.

Credé, M., Tynan, M. C., \& Harms, P. D. (2016). Much ado about grit: A meta-analytic synthesis of the grit literature. Journal of Personality and Social Psychology. Advance online publication. DOI:10.1037/pspp0000102 
Cutler, D. M., \& Lleras-Muney, A. (2006). Education and health: Evaluating theories and evidence. In R. F. Schoeni, J. S. House, G. A. Kaplan, \& H. Pollack (Eds.), Making Americans Healthier: Social and economic policy as health policy (pp. 29-60). New York: Russell Sage Foundation.

Damon, W., \& Lerner, R. (2009). The scientific study of child and adolescent development: Important issues in the field today. In W. Damon \& R. Lerner (Eds.) Child and adolescent: An advanced course. New York: Wiley \& Sons. (pp. 3-13).

Day, J. C., \& Newburger, E. C. (2002). The big payoff: Educational attainment and synthetic estimates of work-life earnings (Current Population Report P23-210). Washington, DC:

\section{U.S. Census Bureau.}

De Castella, K. \& Byrne, D. (2015). My intelligence may be more malleable than yours: The revised implicit theories of intelligence (self-theory) scale is a better predictor of achievement, motivation, and student disengagement. European Journal of Psychology of Education, 30(3), 245-267.

Deutsch, N. L. (2008). Pride in the projects: Teens building identities in urban contexts. New York, NY: New York University Press.

Dixson, D. D., Roberson, C. B., \& Worrell, F. C. (2017). Psychosocial Keys to African American Achievement? Examining the Relationship between Achievement and Psychosocial Variables in High Achieving African Americans. Journal of Advanced Academics, 28(2), 120-140.

Duckworth, A.L, \& Quinn, P.D. (2009). Development and validation of the Short Grit Scale (GritS). Journal of Personality Assessment, 91, 166-174. 
Durlak, J. A., Weissberg, R. P., Dymnicki, A. B., Taylor, R. D., \& Schellinger, K. B. (2011). The impact of enhancing students' social and emotional learning: A meta-analysis of schoolbased universal interventions. Child development, 82(1), 405-432.

Durlak, J. A., Weissberg, R. P., \& Pachan, M. (2010). A meta-analysis of after-school programs that seek to promote personal and social skills in children and adolescents. American Journal of Community Psychology, 45(3-4), 294-309.

Dweck, C.S. (1986). Motivational processes affecting learning. American Psychologist, 41(10), 1040-1048.

Dweck, C. S., Walton, G. M., and Cohen, G. L. (2011). Academic tenacity: Mindsets and skills that promote long-term learning. Seattle, WA: Bill \& Melinda Gates Foundation.

Eccles J.S., Adler, T.F., Futterman, R., Goff, S.B., Kaczala, C.M., Meece, J.L., and Midgley, C. (1983). Expectancies, values, and academic behaviors. In J.T. Spence (Ed.), Achievement and achievement motivation (pp. 75-146). San Francisco: W.H. Freeman.

Farrington, C. A., Roderick, M., Allensworth, E., Nagaoka, J., Keyes, T. S., Johnson, D. W., \& Beechum, N. O. (2012). Teaching adolescents to become learners: The role of noncognitive factors in shaping school performance-A critical literature review. Consortium on Chicago School Research: Chicago, IL.

Farruggia, S. P., Han, C. W., Watson, L., Moss, T. P., \& Bottoms, B. L. (2016). Noncognitive factors and college student success. Journal of College Student Retention: Research, Theory \& Practice, 0, 1-20.

García, E. (2016). The Need to Address Non-Cognitive Skills in the Education Policy Agenda. In Non-Cognitive Skills and Factors in Educational Attainment (pp. 31-64). Sense Publishers. 
Garner, P. W., Mahatmya, D., Brown, E. L., \& Vesely, C. K. (2014). Promoting desirable outcomes among culturally and ethnically diverse children in social emotional learning programs: A multilevel heuristic model. Educational Psychology Review, 26(1), 165-189.

Gutman, L. M., \& Schoon, I. (2013). The impact of non-cognitive skills on outcomes for young people. Education Empowerment Foundations, London.Heckman, J. J. (2008). Schools, skills, and synapses. Economic inquiry, 46(3), 289-324.

Hacker, D. J., Dunlosky, J., \& Graesser, A. C. (Eds). (2009). Handbook of metacognition in education. New York: Routledge.

Hoeschler, P., Balestra, S., \& Backes-Gellner, U. (2018). The development of non-cognitive skills in adolescence. Economics Letters, 163, 40-45. https://doi.org/10.1016/j.econlet.2017.11.012

Hoffman, D. M. (2009). Reflecting on social emotional learning: A critical perspective on trends in the United States. Review of educational research, 79(2), 533-556.

Jones, S. M., \& Bouffard, S. M. (2012). Social and Emotional Learning in Schools: From Programs to Strategies. Social Policy Report. Volume 26, Number 4. Society for Research in Child Development.

Joreskog, K.G. (1999). How large can a standardized coefficient be. Unpublished report. SSI Central, Inc. Retrieved from http://www.ssicentral.com/lisrel/techdocs/HowLargeCanaStandardizedCoefficientbe.pdf

Kline, R. B. (2015). Principles and practice of structural equation modeling (4 ${ }^{\text {th }}$ ed.). New York, NY: Guilford Press.

Lerner, R. M. (1991). Changing organism-context relations as the basic process of development: A developmental contextual perspective. Developmental Psychology, 27 (1), 27-32. 
Lerner, R. M., Leonard, K., Fay, K., \& Issac, S. S. (2011). Continuity and discontinuity in development across the life span: A developmental systems perspective. In K.L. Fingerman, C.A. Berg, J. Smith, \& T.C. Antonucci (Eds.), Handbook of life-span development (pp. 141-160). New York: Springer.

Malecki, C. K., \& Elliot, S. N. (2002). Children's social behaviors as predictors of academic achievement: A longitudinal analysis. School Psychology Quarterly, 17(1), 1-23.

McInerney, D. M. (2008). The motivational roles of cultural differences and cultural identity in self-regulated learning. In D. H. Schunk \& B. J. Zimmerman (Eds.) Motivation and selfregulated learning: Theory, research, and applications, 369-400.

Nagaoka, J., Farrington, C. A., Ehrlich, S. B., \& Heath, R. D. (2015). Foundations for Young Adult Success: A Developmental Framework. Concept Paper for Research and Practice. University of Chicago Consortium on Chicago School Research.

Peterson, N. A., Peterson, C. H., Agre, L., Christens, B. D. \& Morton, C. M. (2011). Measuring youth empowerment: Validation of a Sociopolitical Control Scale for Youth in an urban community context. Journal of Community Psychology, 39, 592-605.

Phinney, J. S., \& Rosenthal, D. A. (1992). Ethnic identity in adolescence: Process, context, and outcome. In G. R. Adams, T. P. Gullotta, \& R. Montemayor (Eds.), Adolescent identity formation (pp. 145-172). Newbury Park, CA: Sage.

Sisk, V. F., Burgoyne, A. P., Sun, J., Butler, J. L., \& Macnamara, B. N. (2018). To What Extent and Under Which Circumstances Are Growth Mind-Sets Important to Academic Achievement? Two Meta-Analyses. Psychological Science, 0956797617739704. 
Tangney, J.P., Baumeister, R.F., Boone, A.L. (2004). High self-control predicts good adjustment, less pathology, better grades, and interpersonal success. Journal of Personality, 41, 271324.

Walton, G.M., and Cohen, G.L. (2011). A brief social-belonging intervention improves academic and health outcomes among minority students. Science, 331, 1447-1451.

Weiner, B. (1979). A theory of motivation for some classroom experiences. Journal of Educational Psychology, 71(1), 3-25.

Weissberg, R. P., Durlak, J. A., Domitrovich, C. E., \& Gullotta, T. P. (2015). Social and emotional learning: Past, present, and future. In Durlak, J. A., Domitrovich, C. E., Weissberg, R. P., Gullotta, T. P., \& Comer, J. (Eds.), Handbook of social and emotional learning: Research and practice, 3-19. Guilford Publications.

Rosseel, Y. (2012). lavaan: An R Package for Structural Equation Modeling. Journal of Statistical Software, 48(2), 1-36. URL http://www.jstatsoft.org/v48/i02/

Thompson, R. B., Corsello, M., McReynolds, S., \& Conklin-Powers, B. (2013). A longitudinal study of family socioeconomic status (SES) variables as predictors of socio-emotional resilience among mentored youth. Mentoring \& Tutoring: Partnership in Learning, 21 (4), 378.391. DOI: 10.1080/13611267.2013.855864

Yeager, D. S., \& Walton, G. M. (2011). Social-psychological interventions in education: They're not magic. Review of educational Research, 81(2), 267-301.

Yeagar, D. S., Hanselman, P. Walton, G. M., Crosnoe, R., Muller, C., Tipton, E., Schneider, B., Hulleman, C., Hinojosa, C., Paunesku, D., Romero, C., Flint, K., Roberts, A., Trott, J., Iachan, R., Buontempo, J., Yang Hooper, S., Murray, J., Carvalho, C., Hahn, R., Ferguson, R., Duckworth, A. L., Dweck, C. S. (2018). Where and for whom can a brief, 
scalable mindset intervention improves adolescents' educational trajectories?

Unpublished manuscript. Retrieved from https://osf.io/r82dw/ (March 1st, 2018).

Zimmerman, B. J., and Schunk, D. H. (Eds.). (1989). Self-regulated learning and academic achievement: Theory, research, and practice. New York: Springer Verlag. 